\title{
14.
}

\section{Mascheroni, G., Ponte, C. \& Jorge, A. (Eds.) (2018). Digital Parenting. The Challenges for Families in the Digital Age. Göteborg: Nordicom.}

\author{
Marisa Mourão
}

Num fundo vermelho repleto de uma imensidão de zeros e uns aparece desenhada uma família em ponto pequeno. É esta a imagem que serve de apresentação ao livro Digital Parenting. The Challenges for Families in the Digital Age editado por Giovanna Mascheroni, Cristina Ponte e Ana Jorge, uma obra sobre a parentalidade nesta era digital.

A capa é, desde logo, uma alusão ao ambiente intensamente povoado pelos media digitais, que, hoje, "são uma parte vital do quotidiano das jovens famílias" (Naab, 2018: 93). Estima-se que um terço dos utilizadores de internet em todo o mundo são menores de 18 anos e há cada vez mais provas empíricas de que as crianças acedem mais cedo à internet (UNICEF, 2017). Além disso, a verdade é que as tecnologias digitais deixaram de desempenhar um papel dito suplementar na vida das crianças para serem, atualmente, "um meio sempre presente no qual e através do qual as crianças (e todos nós) agora vivem as suas vidas" (Livingstone \& Blum-Ross, 2017: 12).

Este cenário traz novas preocupações, mas também novas oportunidades e expectativas, e levanta, naturalmente, distintas problemáticas que têm vindo a ocupar investigadores com particular interesse na relação dos públicos mais jovens com os meios de comunicação, na qual os pais têm um papel essencial. Neste sentido, são evidentes a pertinência e a atualidade deste livro relacionado com as oportunidades e os desafios apresentados às famílias como resultado da proliferação dos media digitais. 
A obra é da Nordicom, organização que tem vindo a dedicar especial atenção à área das crianças, jovens e media, contando com inúmeras publicações neste campo ${ }^{1}$. Em particular, podemos encontrar este livro no espaço dedicado pela instituição ao "The Clearinghouse Yearbook"2, já que é precisamente o anuário de 2018 da International Clearinghouse on Children, Youth and Media, acolhida pela Nordicom entre 1998 e 2018 e com o objetivo de aumentar a consciencialização e o conhecimento sobre a área das crianças, jovens e media ${ }^{3}$.

A edição da obra esteve a cargo, como já foi referido, de Giovanna Mascheroni (Università Cattolica de Milão, Itália), de Cristina Ponte (Universidade NOVA de Lisboa, Portugal) e de Ana Jorge (Universidade Católica, Portugal), investigadoras com um reconhecido trabalho sobre a relação dos mais jovens com os meios digitais, que têm inclusivamente colaborado em projetos internacionais neste domínio, como, por exemplo, o EU Kids Online, focado precisamente no modo como as crianças usam os novos media ${ }^{4}$.

Foi também a cargo destas investigadoras que ficou, obviamente, a introdução da obra, na qual começam por nos localizar no que diz respeito ao conceito que dá título ao livro. Logo no primeiro parágrafo, explicam o significado de parentalidade digital, referindo que:

\begin{abstract}
é um conceito popular ainda que polissémico, que se refere tanto ao modo como os pais estão cada vez mais envolvidos na regulação da relação dos seus filhos com os media digitais (mediação parental), como ao modo como os pais incorporam os media digitais nas suas atividades diárias e práticas parentais e, como ao fazê-lo, desenvolvem formas emergentes de parentalidade. (Mascheroni, Ponte \& Jorge, 2018: 9)
\end{abstract}

As editoras evidenciam, assim, os dois assuntos associados ao conceito - a mediação parental e as práticas digitais dos pais -, para de seguida dedicarem umas breves linhas a cada uma destas questões, fazendo um sistemático enquadramento teórico da temática.

À introdução seguem-se os artigos que compõem este livro e que nos oferecem uma leitura de diversas perspetivas, problemáticas e contextos. São um total de 20 artigos resultantes do contributo de 34 autores. Os investigadores são predominantemente da área dos Media e da Comunicação, mas há também a participação de elementos de outras áreas do conhecimento (Educação, Filosofia e Psicologia), o que contribui para a multidisciplinaridade desta obra. Além disso, apesar da predominância de autores do

\footnotetext{
${ }_{1}^{1}$ Para mais informações, consultar: https://www.nordicom.gu.se/en/about-nordicom

2 Disponível em https://nordicom.gu.se/en/publications/books

3 Informação disponível em https://www.nordicom.gu.se/en/media-research/media-and-information-literacy

4 Para mais informações, consultar: http://www.lse.ac.uk/media-and-communications/research/researchprojects/eu-kids-online
} 
continente europeu, participam nesta obra autores de outros espaços geográficos (América do Norte e do Sul, Ásia e Oceânia).

A esta variedade soma-se a multiplicidade de opções metodológicas presentes, o que também contribui para a pluralidade de olhares apresentados neste livro. Análise do discurso, entrevistas, etnografia, grupos de foco, questionários, e, ainda, estudos longitudinais são algumas das abordagens mobilizadas, em alguns casos, usadas de modo combinado.

A nível temático, os capítulos estão agrupados em três secções com títulos bastante ilustrativos do seu conteúdo: "Digital parenting in context" [Parentalidade digital em contexto], "Parental mediation in practice" [Mediação parental na prática] e "Challenges, risks and opportunities of digital media for parents and children" [Desafios, riscos e oportunidades dos media digitais para os pais e para as crianças].

A primeira secção centra-se tanto na mediação parental como nas práticas digitais dos pais, dois assuntos que, como vimos, estão associados ao conceito de parentalidade digital. A particularidade desta parte da obra é, sem dúvida, a variedade de contextos socioculturais apresentados ao longo dos sete capítulos.

A secção abre com uma visão global apresentada por Sonia Livingstone e Jasmina Byrne, que olham para o modo como os pais de países de diferentes níveis de rendimento lidam com os desafios desta era digital e que refletem sobre o que está e o que poderá ser feito para os apoiar.

De seguida, são-nos apresentadas duas realidades contrastantes, em particular, no que diz respeito ao nível de penetração e proliferação dos media digitais. Sun Sun Lim focase numa prática parental emergente denominada "transcendent parenting", experienciada sobretudo pelos pais de classe média a viver em lares altamente conectados, em que os media digitais facilitam e moldam o modo como estão permanentemente em contacto com os seus filhos. Já Isabel Pavez e Teresa Correa convidam-nos a rumar até um território onde a possibilidade de acesso à internet é recente, apresentando-nos o caso das famílias de comunidades rurais isoladas do Chile, num texto em que exploram o papel desempenhado pelas crianças e jovens na inclusão digital destas famílias.

Os seguintes três capítulos apresentam investigações sobre famílias a viver na Europa. Primeiro, Ingrid Paus-Hasebrink analisa o papel dos media e, em particular, as práticas de mediação nas famílias socialmente desfavorecidas da Áustria ao longo de 12 anos. Depois, o foco volta-se para famílias de grupos minoritários. Sabine Little centra-se no modo como pais de origens culturais e linguísticas distintas a viver no Reino Unido usam a tecnologia para transmitir aos seus filhos a língua que é parte da sua herança cultural. E, por fim, Marketa Zezulkova e Lucie Stastna discutem o papel das experiências 
culturais dos pais na mediação parental, a partir de um estudo com famílias ciganas a viver na República Checa.

Para fechar a secção, é-nos dada uma perspetiva diferente: a dos mais novos. Partindo de uma investigação nos Estados Unidos e de outra em Portugal, Lynn Schofield Clark e Maria José Brites dão conta do ponto de vista dos adolescentes sobre o modo como os pais negoceiam com eles as responsabilidades e os direitos digitais, num capítulo focado na socialização política.

A segunda secção é dedicada à mediação parental, noção que, como é referido na introdução do livro, "indica a variedade de práticas que os pais adotam para gerir e regular o envolvimento dos seus filhos com os media" (Mascheroni, Ponte \& Jorge, 2018: 9).

Esta segunda parte da obra começa com um foco nas crianças mais novas. Para abrir a temática, Thorsten Naab sugere uma abordagem complementar à mediação parental designada "media trusteeship" e aplicada pelos pais especialmente quando os filhos ainda não usam autonomamente os media. Depois, é-nos apresentado um estudo de Yehuda Bar Lev, Nelly Elias e Sharona Levy sobre a mudança no uso dos media por uma criança desde os seis aos 27 meses e os diferentes fatores familiares que influenciaram este processo. E, por fim, Leslie Haddon e Donell Holloway analisam a avaliação feita pelos pais do papel dos ecrãs tácteis na vida de crianças entre os zero e os cinco anos.

Já os dois textos que se seguem apresentam os dois lados da moeda: a perspetiva dos pais e também a das crianças sobre a atividade online destas últimas. Rozane De Cock, Bieke Zaman, Maarten Van Mechelen e Jonathan Huyghe investigam as perspetivas dos pais sobre o envolvimento dos filhos em jogos de azar em comparação com o que os mais novos dizem fazer. Já Lorleen Farrugia e Mary Anne Lauri procuram identificar o conhecimento dos pais sobre o comportamento online dos filhos e os desafios que enfrentam neste campo.

Nos últimos dois textos são apresentados ângulos de análise particulares, num caso, pela escolha dos envolvidos e, noutro caso, pelo território em estudo. No primeiro, Gisela Schubert e Susanne Eggert apresentam-nos um olhar diferente, o dos profissionais que facultam ajuda no âmbito da educação para os media dos mais novos, os quais identificam, no seu domínio de atuação, problemas dos pais e alguns pontos cruciais para auxiliar as crianças. No segundo caso, Jos de Haan, Peter Nikken e Annemarie Wennekers olham para a mediação parental nos Países Baixos, apresentando também o panorama geral das iniciativas implementadas neste contexto. Para terminar, a terceira e última seção foca-se de modo particular nos desafios, riscos e oportunidades associados aos meios digitais, refletindo cada um dos seis textos sobre 
temáticas específicas: produção de rastos digitais das crianças (assunto abordado por Veronica Barassi), regras sobre o tempo despendido em frente aos ecrãs (Alicia BlumRoss e Sonia Livingstone), papel de um grupo de Facebook na vida de um pai com um filho com um síndrome genético raro (Pille Pruulmann-Vengerfeldt), mediação digital do parto (Ranjana Das) e partilha de fotografias e informação dos filhos nos media sociais (questão presente num texto de Maja Sonne Damkjaer e noutro de Ulla Autenrieth).

Alguns dos desafios apresentados neste livro são parte de discussões regulares que ultrapassam os muros da academia, pelo que os textos podem ser um contributo para alargar o debate. A título de exemplo poderemos falar de duas peças publicadas por dois meios de comunicação portugueses na mesma semana do mês de abril de 2019, as quais se relacionam com as temáticas abordadas na última seção desta obra, o que reflete mais uma vez a pertinência e a atualidade da mesma.

Uma das peças, intitulada "Mãe, pai: quem é que vos disse que podiam postar isso sobre mim?", publicada pela revista DN Life, debruça-se sobre a publicação feita pelos pais de conteúdos relativos aos filhos nos media sociais e sobre o facto de os mais novos quererem ter a última palavra sobre este assunto (Pago, 2019). Esta peça relaciona-se, obviamente, com os dois textos associados diretamente a esta questão e ainda com a produção de rastos digitais das crianças através das práticas dos pais. Nos dois capítulos do livro dedicados a esta prática designada "sharenting" é explorada a visão dos pais, trazendo, assim, mais dados para o debate deste desafio. Num dos textos, Damkjaer (2018) concluiu, a partir da sua investigação com pais dinamarqueses, que, apesar de existirem diferentes motivos por detrás da decisão de partilhar, esta prática, no Facebook, desempenha um papel fundamental na (re)produção da autoidentidade dos pais, na aprovação social e na construção e manutenção de laços sociais. No outro capítulo, Autenrieth (2018) refere que não nos podemos focar apenas em fenómenos extremos, pois há pais com práticas de partilha moderadas e que refletem bastante sobre o que partilhar, sentindo-se alguns inseguros e divididos entre a vontade de comunicar e a necessidade de proteger os direitos de privacidade dos seus filhos. Estes capítulos fazem-nos, então, refletir sobre a complexidade do desafio de conjugar os direitos das crianças e os dos pais, pelo que, apesar de ser tentador incentivar os pais a não partilhar nada, isso seria ignorar parte da questão (Blum-Ross, 2016). Portanto, poderá ser relevante a criação de estratégias para apoiar os pais neste domínio, como nos mostra em particular o texto de Autenrieth (2018)5.

Já a notícia "OMS desaconselha exposição das crianças com menos de dois anos a ecrãs", divulgada no Expresso, dá conta do relatório "Orientações sobre atividade física,

\footnotetext{
${ }^{5}$ No capítulo de Ulla Autenrieth (2018) é apresentado um guia desenvolvido no sentido de auxiliar as famílias a discutir questões neste âmbito.
} 
comportamento sedentário e sono para crianças com menos de cinco anos", destacando uma das orientações, na qual "a Organização Mundial de Saúde (OMS) desaconselha a exposição das crianças até aos dois anos a ecrãs e recomenda que dos dois aos quatro anos seja limitada até uma hora diária" (Barros, 2019: s.p.). Esta peça levanta a questão das regras sobre o tempo despendido em frente aos ecrãs, assunto abordado no segundo texto da última seção. Nesse capítulo, Blum-Ross e Livingstone (2018) centram-se nas diretrizes da Academia Americana de Pediatria e na sua influência nas famílias, mas deixam-nos uma reflexão que pode contribuir para alargar o debate a partir da notícia referida. Segundo as autoras, diretrizes como estas baseiam-se em evidencias científicas insuficientes e levam os pais a dar prioridade a medidas restritivas que nem servem o propósito de manter os filhos a salvo, nem contribuem para que estes aproveitem as oportunidades dos meios digitais. Além disso, como lembram, o discurso sobre o tempo em frente ao ecrã leva os pais a focarem-se no relógio, esquecendo-se de pensar sobre a natureza do uso dos media, o modo como interagem com os seus filhos através destes meios ou apresentam bons modelos de hábitos, pelo que sugerem que o apoio aos pais seja voltado para a compreensão do conteúdo, do contexto e das conexões feitas pelas crianças nesse tempo (Blum-Ross \& Livingstone, 2018).

Não podemos oferecer aos pais uma receita com regras simplistas. É necessário, como referido na conclusão do capítulo, incentivá-los a pensar criticamente sobre como podem auxiliar os seus filhos a aproveitar as potencialidades destes meios e a minimizar os riscos (Barron et el., 2009, citados em Blum-Ross \& Livingstone, 2018). Esta é, aliás, no nosso entender, uma questão central quando pensamos neste desafio em particular, mas também noutros desafios desta era digital, sendo essencial o desenvolvimento de ações de sensibilização e de promoção da literacia mediática dos pais para que estes possam auxiliar do melhor modo os seus filhos.

É certo que os debates públicos centrados nas crianças e nos meios de comunicação tendem a obedecer a uma lógica dualística - os media ou são bons ou são maus, as crianças ou são vítimas impotentes ou são consumidores competentes, ou devemos garantir o acesso das crianças aos media ou devemos de protegê-las e mantê-las longe deles -, contudo, pensar nos meios de comunicação como bons ou maus para as crianças acaba por colocá-las na posição de simples recetoras do que os adultos fazem por e para elas (Buckingham, 2009). Por isso, na linha do que defende Buckingham (2009), precisamos de ter em conta os direitos das crianças não enquanto futuros cidadãos, mas enquanto cidadãos no presente. E, neste quadro, importa pensar a importância da educação, que, na perspetiva do especialista, deve ser adicionada ao conjunto de direitos relativos aos media, porque é necessário desenvolver capacidades que permitam exercer os direitos de proteção, de provisão e de participação. Deste 
modo, e considerando que a literacia mediática é hoje "uma das condições essenciais para o exercício de uma cidadania activa e plena" (Recomendação 2009/625/CE), na discussão destes assuntos, interessa não esquecer a relevância da promoção da literacia mediática das crianças, questão que não é, aliás, ignorada no livro Digital Parenting. The Challenges for Families in the Digital Age. Neste sentido, tendo em conta o papel dos pais neste âmbito, é importante o desenvolvimento de estratégias com o objetivo de apoiar os pais na promoção das competências mediáticas dos seus filhos, mas também a implementação de ações nas escolas, um contexto que tem sido apontado como o mais propício ao desenvolvimento destas competências (Pinto, Pereira, Pereira \& Ferreira, 2011).

Por outro lado, é ainda necessário incentivar os pais a pensarem criticamente sobre as suas próprias práticas digitais como, por exemplo, a partilha de informação e imagens dos seus filhos nos media sociais, domínio relativamente ao qual já assinalamos a importância do desenvolvimento de estratégias de apoio. Claro que esta reflexão crítica também reverterá a favor das crianças, mas queremos aqui sublinhar a necessidade do desenvolvimento de ações que não incidam unicamente sobre o modo de auxiliar os filhos, pois isso seria ignorar parte dos desafios apresentados aos pais desta era digital. Em modo de conclusão, poderá dizer-se que este livro é um retrato dos desafios associados à parentalidade num ambiente dominado pelos media digitais. Não é obviamente um retrato totalmente completo, pois seria impossível dar conta da multiplicidade de realidades existentes. Dá-nos, ainda assim, uma imagem ampla do atual cenário, já que não só nos apresenta uma variedade questões associadas à temática, como também dá conta de espaços com diferentes níveis de penetração digital, de distintos espaços geográficos, contextos sociais e culturais. É uma obra que promove o debate, fornece pistas para investigações futuras e, além disso, apresenta indícios e sugestões para a ação/intervenção, o que poderá ser particularmente interessante já que este livro, à imagem dos restantes anuários da International Clearinghouse on Children, Youth and Media, pretende ir além do público académico, alcançando uma variedade de leitores, entre os quais se incluem profissionais da área, organizações não governamentais, decisores políticos e pais.

\section{Referências bibliográficas}

Autenrieth, U. (2018). Family photography in a networked age. Anti-sharenting as a reaction to risk assessment and behaviour adaption. In G. Mascheroni, C. Ponte \& A. Jorge (Eds.), Digital Parenting. The Challenges for Families in the Digital Age (pp. 219231). Göteborg: Nordicom [ebook]. Retirado de

https://www.nordicom.gu.se/en/publikationer/digital-parenting 
Barros, J. P. (2019, 24 de abril). OMS desaconselha exposição das crianças com menos de dois anos a ecrãs. Expresso. Retirado de https://expresso.pt/sociedade/2019-04-24OMS-desaconselha-exposicao-das-criancas-com-menos-de-dois-anos-aecras\#gs.7a0nwo

Blum-Ross, A. (2016, 14 de setembro). Where and when does a parent's right to share end online? [Post em blogue]. Retirado de https://blogs.Ise.ac.uk/parenting4digitalfuture/2016/09/14/where-and-when-does-aparents-right-to-share-end-online/

Blum-Ross, A. \& Livingstone, S. (2018). The Trouble with "Screen Time" Rules. In G. Mascheroni, C. Ponte \& A. Jorge (Eds.) Digital Parenting. The Challenges for Families in the Digital Age (pp. 179-187). Göteborg: Nordicom [ebook]. Retirado de https://www.nordicom.gu.se/en/publikationer/digital-parenting

Buckingham, D. (2009). Os direitos das crianças para os media. In C. Ponte (Ed.), Crianças e Jovens em Notícia (pp. 15-27). Lisboa: Livros Horizonte.

Damkjaer, M. S. (2018). Sharenting = Good Parenting? Four Parental Approaches to Sharenting on Facebook. In G. Mascheroni, C. Ponte \& A. Jorge (Eds.), Digital Parenting. The Challenges for Families in the Digital Age (pp. 209-218). Göteborg: Nordicom [ebook]. Retirado de https://www.nordicom.gu.se/en/publikationer/digitalparenting

Livingstone, S. \& Blum-Ross, A. (2017). Researching children and childhood in the digital age. In P. Christensen \& A. James (Eds.), Research with Children: Perspectives and Practices (pp. 54-70). Abingdon: Routledge. Retirado de http://eprints.Ise.ac.uk/id/eprint/68897

Mascheroni, G., Ponte, C. \& Jorge, A. (2018). Introduction. In G. Mascheroni, C. Ponte \& A. Jorge (Eds.), Digital Parenting. The Challenges for Families in the Digital Age (pp. 9-16). Göteborg: Nordicom [ebook]. Retirado de https://www.nordicom.gu.se/en/publikationer/digital-parenting

Naab, T. (2018). From Media Trusteeship to Parental Mediation. The Parental Development of Parental Mediation. In G. Mascheroni, C. Ponte \& A. Jorge (Eds.), Digital Parenting. The Challenges for Families in the Digital Age (pp. 93-102). Göteborg: Nordicom [ebook]. Retirado de https://www.nordicom.gu.se/en/publikationer/digitalparenting

Pago, A. (2019, 22 de abril). Mãe, pai: quem é que vos disse que podiam postar isso sobre mim? DN Life. Retirado de https://life.dn.pt/familia/mae-pai-quem-e-que-vosdisse-que-podiam-postar-isso-sobre-mim/

Pinto, M., Pereira, S., Pereira, L. \& Ferreira, T. (2011). Educação para os Média em Portugal: Experiências, actores e contextos. Lisboa: Entidade Reguladora para a Comunicação Social. Retirado de http://www.erc.pt/pt/noticias/estudo-sobre-aeducacao-para-os-media-em-portugal-experiencias-actores-e-contextos

Recomendação 2009/625/CE, Recomendação da Comissão Europeia sobre literacia mediática no ambiente digital para uma indústria audiovisual e de conteúdos mais competitiva e uma sociedade do conhecimento inclusiva, de 20 de agosto, Comissão Europeia. 
UNICEF (2017). The State of the World's Children 2017: Children in a Digital World. New York: UNICEF. Retirado de https://www.unicef.org/publications/index_101992.html

Marisa Mourão é mestre em Ciências da Comunicação pela Universidade do Minho, com uma dissertação sobre o potencial da rádio na promoção da literacia mediática em contexto escolar. Colaborou na conceção e gestão do Communitas, Think Tank do Centro de Estudos de Comunicação e Sociedade (CECS) da Universidade do Minho, e, atualmente, é Gestora de Ciência e Tecnologia no CECS.

\marisavmourao@gmail.com 